\title{
Possible involvement of IL-12 expression by Epstein-Barr virus in Sjögren syndrome
}

\author{
M Horiuchi, S Yamano, H Inoue, J Ishii, Y Nagata, H Adachi, M Ono, J N Renard, \\ F Mizuno, Y Hayashi, I Saito
}

\begin{abstract}
Aim-To determine the correlation between interleukin 12 (IL-12) expression and Epstein-Barr virus (EBV) in Sjögren syndrome.

Methods-Indirect immunohistochemical technique, enzyme linked immunosorbent assay (ELISA), and immunoblot analysis were used to investigate IL-12 expression by EBV activation, using 13 surgical specimens and four $B$ cell lines.

Results-Marked expression of IL-12 was found in the epithelial cells and the infiltrating $B$ cells of salivary gland tissues from patients with Sjögren syndrome (six of 10 cases), but not in those from normal individuals (none of three cases). A striking topographic correlation between IL-12 and EBV was found. In addition, levels of IL-12 production by $B$ cell lines were clearly enhanced by EBV activation in vitro.

Conclusions-IL-12 expression closely reflects the intracellular event of EBV activation in Sjögren syndrome, and may contribute to the $T$ helper cell type 1 (Th1) cytokine overexpression seen in this disease.

(F Clin Pathol 1999;52:833-837)
\end{abstract}

Department of

Microbiology, Tokyo Medical University,

6-1-1, Shinjuku,

Shinjuku-ku, Tokyo,

Japan

M Horiuchi

$\mathrm{H}$ Inoue

J Ishii

Y Nagata

H Adachi

J N Renard

F Mizuno

Department of Ophthalmology, Tokai University School of Medicine, Isehara, Kanagawa, Japan M Ono

Department of Pathology, Tokushima University School of Dentistry, 3-18-15, Kuramotocho,

Tokushima 770-8503,

Japan

S Yamano

Y Hayashi

I Saito

Correspondence to: Dr Saito.

email:

saito@jp.interramp.com

Accepted for publication 1 June 1999
Keywords: IL-12; Epstein-Barr virus; Sjögren syndrome

Sjögren syndrome is an autoimmune disease characterised by lymphocytic infiltration into lacrimal and salivary glands leading to symptomatic dry eyes and mouth. ${ }^{1}$ Immunohistochemical studies have shown that the majority of infiltrating lymphocytes around the labial salivary and lacrimal glands are CD4+ T cells. ${ }^{2}$ It has been reported that salivary gland CD4+ T cells produced more interleukin (IL)-2, $\gamma$ interferon (IFN- $\gamma$ ), and IL-10 mRNAs than peripheral blood CD 4+ T cells obtained from the same patients, whereas they produced little IL- 4 and IL-5 mRNA. ${ }^{3}$ Similarly, Ohyama et al reported that raised levels of cytokine mRNA including IL-2, IFN- $\gamma$, and IL-10 in the labial salivary glands of patients with Sjögren syndrome. ${ }^{4}$ These results indicate that $\mathrm{T}$ helper cell type 1 (Th1) cytokines are essential in the induction or maintenance of Sjögren syndrome.

IL-12 is a heterodimeric cytokine originally identified and purified as a product of EpsteinBarr virus (EBV) transformed B cell lines. ${ }^{5}$ In human peripheral blood, monocytes/ macrophages are the major producers of IL-12, together with B cells and other minor populations of HLA-DR+ accessory cells. ${ }^{6}$ It has been suggested that IL-12 has a role in the induction of IFN- $\gamma$ production, in the development of $\mathrm{Th} 1,{ }^{78}$ and in the generation of cytotoxic $\mathrm{T}$ lymphocytes. ${ }^{9} \mathrm{EBV}$ is a widely occurring virus of the herpes family that infects the epithelial cells of the salivary glands and oropharyngeal tissue and the B cells. After the primary infection, the virus remains latent in the host, and occasionally becomes reactivated. ${ }^{10-16} \mathrm{EBV}$ antigen and its DNA have been found in salivary gland tissues of patients with Sjögren syndrome at levels well above the background levels for latent infection. ${ }^{17-19}$ Infectious EBV is present in both the saliva of Sjögren patients ${ }^{20}$ and in culture supernatants of $B$ cell lines established from such patients. ${ }^{21}$ Patients with Sjögren syndrome have raised levels of antibodies against EBV RNA protein complexes and against EBV antigens. ${ }^{22} 23$ Taken together, these observation suggest that a reactivated EBV infection may play a role in Sjögren syndrome, contributing to the initiation or perpetuation of an autoimmune response in the target organs. However, the pathological role of the virus remains obscure. Previous experiments identified an EBV gene BZLF1, the product of which-ZEBRA-switches the virus from a latent to a replicative state. ${ }^{24-26}$ ZEBRA is itself sufficient to disrupt latency. ${ }^{27}$ Thus evidence for an association between EBV activation and Sjögren syndrome has been accumulating, but our present study is the first to report ZEBRA expression in salivary glands from patients with Sjögren syndrome.

As IL-12 may induce environmentally stimulated inflammatory responses, we have investigated IL-12 expression by EBV in Sjögren salivary glands and whether or not EBV activation is able to induce IL-12 expression in vitro.

\section{Methods}

PATIENTS

All patients were seen at the Tokyo Medical University Hospital. Ten patients with primary Sjögren syndrome underwent minor salivary gland biopsies to confirm the diagnosis. ${ }^{28}$ The biopsies revealed a focus score of $>2$, but did not show evidence of lymphoma in routine histological analysis. Each of these patients had keratoconjunctivitis sicca with decreased tear production $(<5 \mathrm{~mm}$ on Schirmer test with anaesthesia). Corneal and conjunctival epithelia showed positive rose bengal and fluorescein staining. Decreased secretion of saliva was confirmed by gum test results of $<5 \mathrm{ml}^{29}$ These patients had not received glucocorticoids or immunosuppressive agents for at least six months before biopsy. All were women, and their mean age was 47 years (range 23 to 66 years).

As controls, labial salivary gland biopsy specimens were also obtained from three patients with mucoceles who had no clinical or 
laboratory evidence of systemic autoimmune disease. These labial salivary glands were histologically normal.

IMMUNOHISTOCHEMICAL STAINING

The labial salivary glands were immediately placed in OCT compound (Miles), snap frozen in liquid nitrogen, and stored $-80^{\circ} \mathrm{C}$. Cryostat sections $(4 \mu \mathrm{m})$ from each block were transferred onto glass slides for immunohistochemical analysis. Briefly, frozen sections were air dried for 10 minutes, fixed in acetone for 10 minutes, rinsed in phosphate buffered saline (PBS), and incubated with an appropriate blocking agent (Vector) for 20 minutes. They were then incubated for 60 minutes with the following antibodies: purified mouse monoclonal antibodies to human IL-12 p35 (PharMingen), EBV encoded ZEBRA (Dako), CD3, CD 4, CD8, CD14, CD20, CD21 (Coulter), or cytokeratin (Becton Dickinson). Antibodies of the same isotype with irrelevant antibody activity were used as negative controls. After rinsing, the sections were reacted with biotinylated goat antimouse (IgG + IgM) antibody (Tago), followed by peroxidase conjugated avidin-biotin complex (Vector) and then the substrate 3.3'-diaminobenzadine (Sigma). All antibodies were diluted to give optimal staining results. Sections were routinely counterstained with haematoxylin.

CELL LINES AND CULTURE CONDITIONS

Four B cell lines (Akata, B95-8, BJAB, and Ramos) were obtained from the American Type Culture Collection. All of these cell lines are of human origin except for B95-8, which is of marmoset monkey origin. All cell lines were cultured in RPMI 1640 containing penicillin (100 units $/ \mathrm{ml})$, streptomycin $(100 \mu \mathrm{g} / \mathrm{ml})$, glutamine $(10 \mathrm{mg} / \mathrm{ml})$, and $10 \%$ fetal calf serum (FCS; Gibco).

ELISA FOR IL-12 p40

Four B cell lines were stimulated $\left(10^{6} \mathrm{cells} / \mathrm{ml}\right.$, $37^{\circ} \mathrm{C}$ ) in a 24 well plate with $12-\mathrm{O}$ tetradecanoylphorbol 13-acetate (TPA, 50 $\mathrm{ng} / \mathrm{ml})$ or antihuman IgG $(100 \mu \mathrm{g} / \mathrm{ml})$ at 24 and 48 hours. Then, for the detection of immunoreactive IL-12 p40 secreted by four B cell line cultures, a commercially available ELISA kit ( $\& \& D$ Systems) was used which enabled the specific detection of IL-12 p40 proteins.

IMMUNOBLOT ANALYSIS FOR ZEBRA

Two B cell lines, TPA treated B95-8 and anti-IgG treated Akata, were cultured $\left(10^{6}\right.$ cells/ $\mathrm{ml}, 37^{\circ} \mathrm{C}$ ) at the indicated time points. They were then solubilised in lysis buffer $(300 \mu \mathrm{l}$ PBS containing 1\% Triton X-100 (Sigma), EDTA (1 $\mathrm{mM}$ ), leupeptin ( $1 \mathrm{mg} / \mathrm{ml}$; Sigma), aprotonin (5 $\mathrm{mg} / \mathrm{ml}$; Sigma), and PMSF (50 mg/ml; Sigma), $\mathrm{pH}$ 7.5. Following solubilisation, the samples were clarified by centrifugation at $10000 \mathrm{~g}$ for 10 minutes. An aliquot was then removed for protein assay using a commercially available kit (Bio-Rad), and the remainder of the lysate was frozen at $-20^{\circ} \mathrm{C}$ pending analysis. For electrophoretic fractionation, an equal volume of lysate (containing $30 \mu \mathrm{g}$ of protein) or protein standards (Bio-Rad) was mixed with $2 \times$ electrophoresis buffer containing sodium dodecyl sulphate (SDS; 4\%), Tris- $\mathrm{HCl}$ (125 mM, $\mathrm{pH}$ 6.8), glycerol (20\% vol/vol), and bromophenol blue $(0.005 \%)$, and fractionated on a $10 \%$ Tris/glycine gel at $150 \mathrm{~V}$. Following electrophoresis, the samples were transferred to PVDF membrane, blocked, and then incubated with mouse monoclonal antibody against human anti-IL-12 p40 (R\&D Systems).

\section{Results}

IMMUNOHISTOLOGICAL ANALYSIS OF IL-12

EXPRESSING CELLS IN SJÖGREN SALIVARY GLANDS To analyse the expression of IL-12 in the salivary glands of patients with Sjögren syndrome, we stained frozen sections of salivary gland tissues with mouse anti-IL-12 antibody using an immunohistological technique. In six of 10 cases, Sjögren salivary gland tissues showed strong reactivity with anti-IL-12 antibody. Positive staining was present in the cytoplasm of most epithelial cells (acini or ductal structures) and many scattered lymphocytes (fig $1 \mathrm{~A}, \mathrm{~B}$, and $\mathrm{C}$ ). Based on this reactivity in serial sections of tissue stained with anti-CD20 and anti-CD21 antibodies (B cell markers) and anticytokeratin antibody (epithelial cell marker), respectively, and their lack of reactivity with anti-CD3 antibody ( $\mathrm{T}$ cell marker) and anti-CD14 (macrophage marker), the stained cells appeared to be epithelial cells and B cells. No staining with anti-IL-12 antibody was detected in the normal salivary glands $(\mathrm{n}=3)$, and no cells were stained an isotype matched rabbit IgG (fig 1D).

As the detection of EBV encoded EBVZEBRA was carried out on one of the serial sections, assessment of the relation between IL-12 expression and EBV-ZEBRA localisation was possible. A striking correlation between EBV-ZEBRA positive cells and IL-12 positive cells was observed in the Sjögren salivary glands. EBV-ZEBRA was detected in five of 10 Sjögren salivary gland biopsy specimens. In normal salivary glands, no EBV-ZEBRA expression was detected $(n=3)$. EBV-ZEBRA positive cells were found among the many infiltrating lymphocytes and in most epithelial cells of the Sjögren salivary glands (fig $2 \mathrm{~A}$ ).

Interestingly, the localisation of EBVZEBRA positive cells (fig $2 \mathrm{~B}$ ) was almost the same as that of IL-12 positive cells (fig 2C). All the EBV-ZEBRA positive areas were also positive for IL-12.

INDUCTION OF IL-12 SECRETION IN B CELL LINES The stimulatory effect of EBV activation on IL-12 secretion was investigated by ELISA. Four B cell lines were cultured $\left(10^{6} \mathrm{cells} / \mathrm{ml}\right.$, $37^{\circ} \mathrm{C}$ ) at 24 and 48 hours with TPA or anti-IgG, and IL-12 levels in culture supernatants were determined (table 1 ). The results showed that an incremental change in IL-12 secretion occurred in both TPA treated B95-8 and anti-IgG treated Akata 24 hours after stimulation (mean SEM IL-12 secretion without TPA $<31.2 \mathrm{pg} / \mathrm{ml}$, with TPA $128 \mathrm{pg} / \mathrm{ml}$ $(n=5), p<0.005$; without anti-IgG $<31.2$ 
$\mathrm{pg} / \mathrm{ml}$, with anti-IgG $135 \mathrm{pg} / \mathrm{ml} \quad(\mathrm{n}=5)$, $\mathrm{p}<0.005)$. In contrast, no stimulatory effect was found in EBV negative Burkitt lymphoma $\mathrm{BJAB}$ and Ramos.
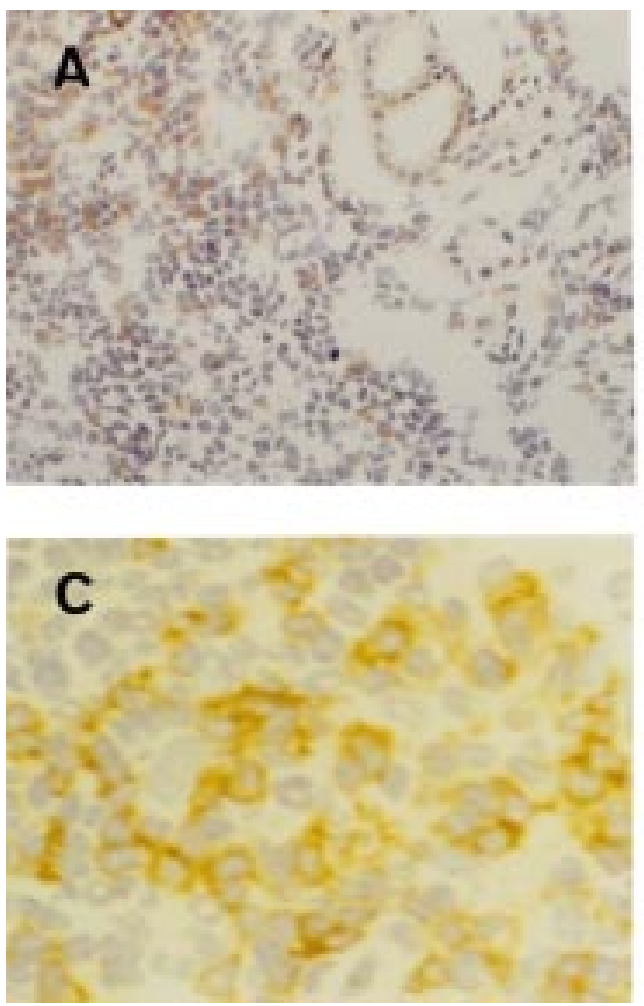

Figure 1 Immunostaining of salivary gland specimens from patients with Sjögren syndrome. Cryostat-frozen serial sections were fixed in cold acetone, stained with mouse anti-IL-12 antibody and mouse anti-ZEBRA antibody, and examined by immunohistological techniques. Numerous anti-IL-12 positive epithelial cells (acini and ductal structures) and lymphoid cells are seen in salivary gland biopsy specimens from patients with Sjögren syndrome $(A-C)$. No cells stained with isotype matched mouse IgG (D). (Magnification $\times 89$ in $A, \times 359$ in B-D.)
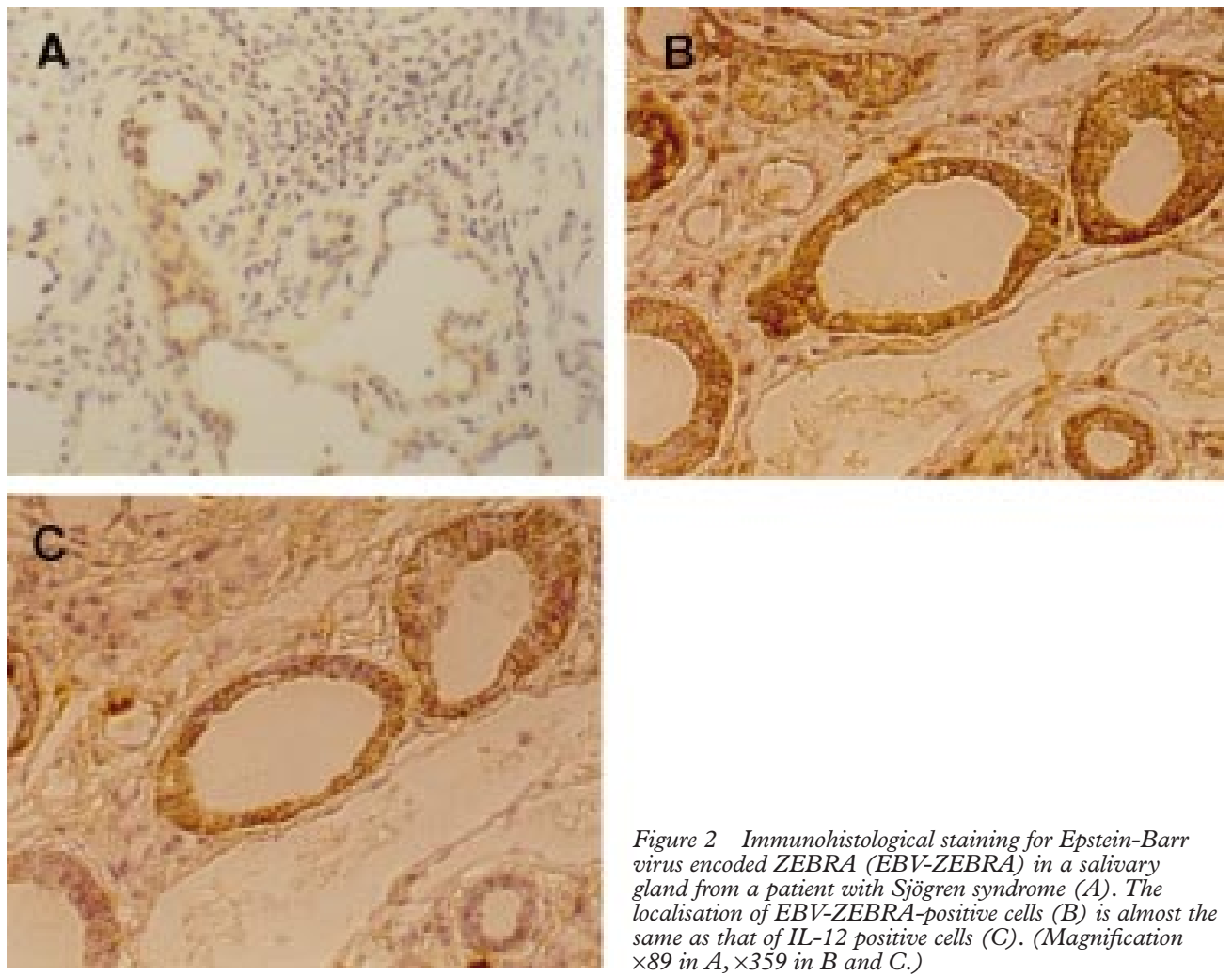

Figure 2 Immunohistological staining for Epstein-Barr virus encoded ZEBRA (EBV-ZEBRA) in a salivary gland from a patient with Sjögren syndrome $(A)$. The localisation of EBV-ZEBRA-positive cells $(B)$ is almost the same as that of $I L-12$ positive cells $(C)$. (Magnification $\times 89$ in $A, \times 359$ in $B$ and $C$.) 
Table 1 Analysis of interleukin 12 (IL-12) secretion in B cell lines by enzyme linked immunosorbent assay (ELISA)

\begin{tabular}{llllll}
\hline & \multicolumn{2}{l}{ Unstimulated } & & \multicolumn{2}{l}{ Stimulated } \\
\cline { 2 - 3 } \cline { 5 - 6 } Responder cells & $24 h$ & $48 h$ & & $24 h$ & $48 h$ \\
\hline Akata & $<31.2$ & $<31.2$ & & $135(31)$ & $141(40)$ \\
B95-8 & $<31.2$ & $<31.2$ & & $128(24)$ & $135(32)$ \\
BJAB & $<31.2$ & $<31.2$ & & $<31.2$ & $<31.2$ \\
Ramos & $<31.2$ & $<31.2$ & & $<31.2$ & $<31.2$ \\
\hline
\end{tabular}

Values are $\mathrm{pg} / \mathrm{ml}$ (mean (SEM)).

The expression of IL-12 p40 in four B cell lines is summarised. Unstimulated or 12-O-tetradecanoylphorbol 13-acetate (TPA $50 \mathrm{ng} / \mathrm{ml}$ ) stimulated B95-8 and BJAB, Ramos, and antihuman$\operatorname{IgG}(100 \mu \mathrm{g} / \mathrm{ml})$ stimulated Akata were cultured for 24 and 48 hours. The supernatants were collected at the indicated time and IL-12 p40 was measured by ELISA.

immunoblot assay for detection of ZEBRA. A substantial expression of ZEBRA was detected in both cell lines 10 hours after stimulation, and increased steadily thereafter (fig 3 ). In the absence of stimulation, no ZEBRA expression was observed in either cell line (data not shown).

\section{Discussion}

Previous evidence for EBV reactivation in patients with Sjögren syndrome includes the presence of EBV antigen ${ }^{17}$ and raised levels of EBV DNA ${ }^{17-19}$ in salivary gland tissues and active production of virus in the saliva ${ }^{20}$ or from B cell lines established from peripheral blood mononuclear cells. ${ }^{21}$ Antibodies against EBV antigens are also raised in Sjögren sera. ${ }^{21-23}$ Another defined manifestation of active EBV infection is the presence of circulating infected $B$ cells that can transform into B cell lymphomas. ${ }^{30-32}$ Thus Sjögren patients show many signs of active, uncontrolled EBV reactivation. In this study, we have shown that most epithelial cells and infiltrated B cells in Sjögren salivary glands had the capacity to express ZEBRA.

Investigation of the relation between IL-12 and EBV in closely parallel sections showed that EBV-ZEBRA positive samples were also positive for IL-12. A close topographic association of EBV-ZEBRA and IL-12 expression in Sjögren salivary glands was indicated. In relation to the production of IL-12 by nonhaemopoietic cells, Aragane et al showed that stimulated human keratinocytes and keratinocyte cell lines have the capacity to express IL-12. ${ }^{33}$ Moreover, Kang et al reported that epidermal Langerhans cells, in particular cultured Langerhans cells maturing into dendritic cells, expressed IL-12 mRNA. ${ }^{34}$ They suggested that this was one mechanism behind the high potency of the dendritic antigen presenting cell for initiating Th1 type immune

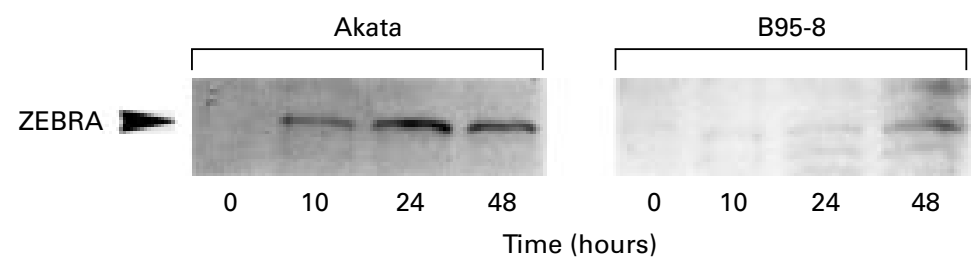

Figure 3 Immunoblot analysis of ZEBRA expression in two B cell lines. Immunoblotting was performed from the cell lysate of Akata, stimulated with anti-IgG, or of B95-8, stimulated with 12-O-tetradecanoylphorbol 13-acetate (TPA) at the indicated time. responses under appropriate conditions. Interestingly, Fox et al reported the presence of HLA-DR antigens on salivary gland epithelial cells and showed that this induction might be caused by IFN $-\gamma .^{35}$ Thus epithelial cells and infiltrated B cells in Sjögren salivary glands may be important mediators of IL-12 induced Th1 development.

Given that immunohistological data cannot be generated in vivo, we investigated the induction of IL-12 in Sjögren salivary glands using B cell lines. Our results showed IL-12 secretion from stimulated EBV infected lymphoma cell lines, Akata and B95-8, was associated with EBV-ZEBRA expression on western blot analysis. These findings suggest that there is a close relation between IL-12 production and EBV activation. Hsu et al reported that the virally encoded genes can modulate lymphokine expression, ${ }^{36}$ and there is further evidence for an association between EBV infection and cytokine production. ${ }^{37-39}$

As previously reported, interaction between two inflammatory cytokines, such as IFN- $\gamma$ and tumour necrosis factor $\alpha$, induces IL- 6 production from human salivary gland cell line. ${ }^{40}$ In addition, Yoshida et al reported that IFN- $\gamma$ was capable of inducing IL-12 mRNA. $^{41}$ If $\mathrm{EBV}$ alone is not sufficient to lead to IL-12 expression, it may be one of many cofactors. It is known that Sjögren salivary glands express increased levels of cytokines compared with normal salivary glands. ${ }^{3}$ Therefore IL-12 expression in Sjögren syndrome may result from EBV activation and cytokine network.

Several properties that may be relevant to the initiation and perpetuation of the pathogenesis of Sjögren syndrome are now known to be present in the salivary glands of affected patients, ${ }^{42}{ }^{43}$ but not in other salivary gland conditions or in normal salivary glands. These include intense lymphocytic infiltration, destruction of epithelial cells, abnormally high levels of EBV and EBV antigen, production of infectious EBV in saliva, de novo expression of HLA-DR on cell surfaces, and ectopic expression of IL-12. These observation are consistent with several scenarios in which EBV plays an important role in the initiation or continuation of immune system damage in salivary and lacrimal glands. We thus propose that IL-12 is a new member of the group of known factors that are overexpressed in Sjögren syndrome, and possibly induced by EBV activation.

\section{CONCLUSIONS}

In summary, our study shows that epithelial cells and infiltrated B cells in salivary glands from patients with Sjögren syndrome have the capacity to express IL-12 associated with EBV activation. These findings suggest that the mutual stimulation of infiltrated lymphocytes and salivary gland epithelial cells through the production of cytokine maintains dominant expression of the Th1 type cytokine in Sjögren salivary glands, giving rise to the eventual destruction of the target organ. A more thorough understanding of the complex consequences of Sjögren syndrome might lead to a possible therapeutic application for cytokine 
agonists and antagonists to disrupt the cytokine network and inhibit the initiation and progression of the disease.

1 Bloch J, Buchanan W, Wohl M, et al. Sjögren's syndrome: a clinical, pathological and serological study of 62 cases. Medicine (Baltimore) 1965;44:187-231.

2 Adamson TC, Fox RI, Frisman DM, et al. Immunohistologic analysis of lymphoid infiltrates in primary Sjögren's syndrome using monoclonal antibodies. F Immunol 1983; 130:203-8.

3 Fox RI, Kang H-L, Ando D, et al. Cytokine mRNA expression in salivary gland biopsies of Sjögren's syndrome. $\mathcal{F}$ Immunol 1994;152:5532-9.

4 Ohyama Y, Nakamura S, Matsuzaki G, et al. Cytokine messenger RNA expression in the labial salivary glands of patients with Sjögren's syndrome. Arthritis Rheum 1996;39:

5 Kobayashi M, Fitz L, Ryan M, et al. Identification and purification of natural killer cell stimulatory factor (NKSF), a cytokine with multiple biologic effects on human lymphocytes. $\mathcal{F}$ Exp Med 1989;170:827-45.

6 D'Andrea A, Rengaraju M, Valiante NM, et al. Production of natural killer cell stimulatory factor (interleukin-12) by peripheral blood mononuclear cells. F Exp Med 1992;176: 1387-98.

7 Manetti R, Parronchi P, Giudizi MG, et al. Natural killer cell stimulatory factor (NKSF/IL-12) induces Th1-type specific immune responses and inhibits the development of IL-4 producing Th cells. I Exp Med 1993;177:1199-204.

8 Hsieh C-S, Macatonia SE, Tripp CS, et al. Development of TH1 CD $4+\mathrm{T}$ cells through IL-12 produced by Listeria-induced macrophages. Science 1993;260:547-9.

9 Gately MK, Wolitzky AG, Quinn PM, et al. Regulation of human cytolitic lymphocyte responses by interleukin-12. human cytolitic lymphocyte resp

10 Morgan DG, Niederman JC, Miller G, et al. Site of EpsteinBarr virus replication in the oropharynx. Lancet 1979;ii: $1154-7$.

11 Wolf H, Haus M, Wilmes E. Persistence of Epstein-Barr virus in the parotid gland. F Virol 1984;51:795-8.

12 Chang R, Lewis J, Abilguard C. Prevalence of oropharyngeal excreters of leukocyte-transforming agents among a human population. N Engl f Med 1973;289:1325-9.

13 Klein G. The Epstein-Barr virus. In: Kaplan A, ed. The herpes virus. New York: Academic Press, 1973.

14 Birkenbach $M$, Tong X, Bradbury LE, et al. Characterization of an Epstein-Barr virus receptor on human epithelial cells. $\mathcal{E}$ Exp Med 1992;176:1405-14.

15 Chang R, Lewis J, Reynold R, et al. Oropharyngeal excretion of Epstein-Barr virus by patients with lymphoproliferative disorders and by recipients of renal homproliferative disorders and by recipients
ografts. Ann Intern Med 1978;88:34-40.

$16 \mathrm{Li} \mathrm{QX}$, Young LS, Niedobitek G, et al. Epstein-Barr virus infection and replication in a human epithelial cell system. Nature 1992:356:347-50.

17 Fox RI, Pearson G, Vaughan JH. Detection of Epstein-Barr virus-associated antigens and DNA in salivary gland biopsies from patients with Sjögren's syndrome. F Immuno 1986;137:3162-8

18 Saito I, Servenius B, Compton T, et al. Detection of Epstein-Barr virus DNA by polymerase chain reaction in blood and tissue biopsies from patients with Sjögren's syndrome. F Exp Med 1989;169:2191-8.

19 Mariette X, Gozlan J, Clerc D, et al. Detection of Epstein-Barr virus DNA by in situ hybridization and polymerase chain reaction in salivary gland biopsy specimens from patients with Sjögren's syndrome. Am $\mathcal{F}$ Med 1991;90:286-94.

20 Yamaoka K, Miyasaka N, Yamamoto K. Possible involvement of Epstein-Barr virus in polyclonal $\mathrm{B}$ cell activation in Siögren's syndrome. Arthritis Rheum 1988;31:1014-21.

21 Tateishi M, Saito I, Yamamoto K, et al. Spontaneous production of Epstein-Barr virus by B lymphoblastoid cell lines obtained from patients with Sjögren's syndrome. Arthritis Rheum 1993:36:827-35.

22 Tan EM. Autoantibodies to nuclear antigens (ANA) : their immunobiology and medicine. Adv Immunol 1983;33:167240.

23 Fox RI, Scott S, Houghton R, et al. Synthetic peptide derived from the Epstein-Barr virus encoded early diffuse antigen (EA-D) reactiv

24 Chevallier-Greco A, Manet E, Chavrier P, et al. Both Epstein-Barr virus (EBV)-encoded trans-acting factors, EB1 and EB2, are required to activate transcription from an EBV early promoter. EMBO $\mathcal{f} 1986 ; 5: 3243-9$.

25 Countryman J, Jenson H, Seibl R, et al. Polymorphic proteins encoded within BZLF1 of defective and standard EpsteinBarr viruses disrupt latency. F Virol 1987;61:3672-9.

26 Countryman J, Miller G. Activation of expression of latent Epstein-Barr herpesvirus after gene transfer with a small cloned subfragment of heterogenous viral DNA. Proc Natl Acad Sci USA 1985;82:4085-9.

27 Takada K, Shimizu N, Sakuma S, et al. Trans activation of the latent Epstein-Barr virus (EBV) genome after transfection of the EBV DNA fragment. F Virol 1986;57:1016-22.

28 Fox RI, Saito I. Criteria for diagnosis of Sjögren's syndrome. Rheum Dis Clin North Am 1994;20:391-407.

29 Fujibayashi T. Diagnosis and management of dry mouth associated with Sjögren's syndrome. In: Homma M, Sugai $\mathrm{S}$, Tojo T, et al, eds. Sjögren's syndrome state of arts. Amsterdam: Kugler, 1994:53-9.

30 Menezes J, Jondal M, Leibold W, et al. Epstein-Barr virus interactions with human lymphocyte subpopulations: virus adsorption, kinetics of expression of Epstein-Barr virusassociated nuclear antigen, and lymphocyte transformation. Infect Immun 1976;13:303-10.

31 Fox RI, Chilton T, Scott S, et al. Potential role of Epstein-Barr virus in Sjögren's syndrome. Rheum Dis Clin North Am 1987:13:275-92.

32 Pisa P, Cannon MJ, Pisa EK, et al. Epstein-Barr virus induced lymphoproliferative tumors in severe combined immunodeficient mice are oligoclonal. Blood 1992;79:173-9.

33 Aragane Y, Riemann H, Bhardwaj RS, et al. IL-12 is expressed and released by human keratinocytes and epidermoid carcinoma cell lines. F Immunol 1994;153: 5366-72.

34 Kang K, Kubin M, Cooper KD, et al. IL-12 synthesis by human Langerhans cells. F Immunol 1996;156:1402-7.

35 Fox RI, Bumol T, Fantozzi R, et al. Expression of histocompatibility antigen HLA-DR by salivary gland epithelial cells in Sjögren's syndrome. Arthritis Rheum 1986;29:1105-11.

36 Hsu DH, de Wall Malefyt R, Fiorentino DF, et al. Expression of interleukin 10 activity by Epstein-Barr virus protein BCRF 1. Science 1990;250:830-2.

37 Nakagomi H, Dolcetti R, Bejarano MT, et al. The EpsteinBarr virus latent membrane protein-1 (LMP-1) induce interleukin-10 production in Burkitt lymphoma lines. Int $\mathcal{F}$ Cancer 1994;57:240-4.

38 Lotz M, Tsoukas CD, Fong S, et al. Release of lymphokines after infection with Epstein-Barr virus in vitro. F Immunol 1986;136:3643-8.

39 Klein SC, Kube D, Abts H, et al. Promotion of IL-8, IL-10, TNF $\alpha$ and TNF $\beta$ production by EBV infection. Leukemia Res 1996;20:633-6.

40 Joseph K, Rafi N, Shlomo B, et al. Cytokine modulates nterleukin- 6 production by human salivary gland cell lines. Cell Immunol 1994;159:211-19.

41 Yoshida A, Koide Y, Uchijima M, et al. IFN- $\gamma$ induces IL-12 mRNA expression by a murine macrophage cell line, J744. Biochem Biophys Res Commun 1994;198:857-61.

42 Garry RF, Fermin CD, Hart DJ, et al. Detection of a human intracisternal A-type retroviral particle antigenically related to HIV. Science 1990;250:1127-9.

43 Haddad J, Deny P, Munz-Gotheil C, et al. Lymphocytic sialadenitis of Sjögren's syndrome associated with chronic hepatitis C virus liver disease. Lancet 1992;339:321-3. 